Short communication

\title{
A study of the temperature effect on Hantzsch reaction selectivity using Mn and Ce oxides under solvent-free conditions
}

\author{
Oriana D'Alessandro, Ángel G. Sathicq, Jorge E. Sambeth, Horacio J. Thomas, Gustavo P. Romanelli * \\ Centro de Investigación y Desarrollo en Ciencias Aplicadas “Dr. Jorge J. Ronco” (CINDECA-CCT-CONICET), Universidad Nacional de La Plata, Calle 47 N²57, B1900AJK La Plata, Argentina
}

\section{A R T I C L E I N F O}

\section{Article history:}

Received 11 September 2014

Received in revised form 24 October 2014

Accepted 20 November 2014

Available online 21 November 2014

\section{Keywords:}

Cerium and manganese oxides

Hantzsch reaction

1,4-Dihydropyridine

2-Phenylpyridine

Green chemistry

\begin{abstract}
A B S T R A C T
In this communication, four materials $\left(\mathrm{CeO}_{2}, \mathrm{CeO}_{2}(\mathrm{Cu}), \mathrm{MnO}_{x}\right.$, and $\left.\mathrm{MnO}_{\mathrm{x}}(\mathrm{Cu})\right)$ were prepared, characterized and tested as catalysts, in solvent-free conditions, for the multicomponent Hantzsch reactions to obtain alternatively the 1,4-dihydropyridine or 2-phenylpyridine depending on the reaction conditions. 1,4-Dihydropyridine $\mathbf{4}$ was the main product formed at $80{ }^{\circ} \mathrm{C}(76 \%)$, and 2-phenylpyridine 7 was the main product at $40{ }^{\circ} \mathrm{C}(91 \%)$, in oxidant-free conditions, using $\mathrm{CeO}_{2}$ catalyst. It is the first report that shows that, not only the temperature but also the nature of the catalyst may change the product selectivity in Hantzsch reactions.
\end{abstract}

(c) 2014 Published by Elsevier B.V.

\section{Introduction}

A multicomponent reaction (MCR) is defined as three or more different starting materials that react to form a product, where most, if not all of the atoms, are incorporated in the final product. From an environmental perspective, the traditional methods of performing chemical synthesis are unsustainable, and MCRs provide an important solution since they are more cost-effective, effective and less wasteful. As one of the known MCRs, Hantzsch reaction has attracted much attention on the synthesis of 1,4-dihydropyridines due to their relevant biological activities and pharmacological uses [1-3].

In this regard, metal oxides represent one of the most important categories of solid catalysts, either as active phases or as supports. Metal oxides are utilized for their acid-base and redox properties and represent an important family of materials used in heterogeneous catalysis [4].

Manganese oxides, including $\mathrm{MnO}, \mathrm{MnO}_{2}$, and $\mathrm{Mn}_{3} \mathrm{O}_{4}$, are intriguing composites used in organic synthesis as catalyst in several transformations, for example, oxidation of alcohols and hydroxy compounds, benzylic acid-type rearrangement, dehydrogenation, oxidative aromatization, and oxidation of amines [5].

Meanwhile, cerium (IV) oxide has been extensively used as a catalyst in different transformations, for example, methane oxidation [6], $\mathrm{N}$-formylation of amines [7], and 1H-benzo [g] pyrazolo [3,4-b] quinoline-5,10-dione [8]. Our research group has studied the use of

\footnotetext{
* Corresponding author.

E-mail address: gpr@quimica.unlp.edu.ar (G.P. Romanelli).
}

manganese oxides $\left(\mathrm{MnO}_{\mathrm{x}}\right)$ and cerium IV oxides in VOC (volatile organic compounds) abatement [9] and water-gas shift reaction, respectively [10].

Moreover, in recent years, much attention has been paid to the synthesis of 1,4-dihydropyridines (1,4-DHPs) due to their relevant biological activity [11-13]. The classical methods for the synthesis of 1,4-DHPs is the Hantzsch multicomponent synthesis between an aldehyde, a 1,3dicarbonyl compound and a source of ammonia, for example, ammonium acetate or an amine in the presence of different acid-basic catalysts [14].

Recently the Cao groups reported the asymmetric synthesis of 2arylpyridines. These compounds could be obtained as a major product in the Hantzsch reaction, by the one-pot multicomponent reaction of benzaldehyde, ethyl acetoacetate and ammonium acetate, at room temperature and long time periods, under solvent, heat, catalysis and oxidant-free conditions [15].

In this communication, we present a study of the multicomponent reaction between benzaldehyde, ethyl acetoacetate, and ammonium acetate in the selective synthesis of 1,4-dihydropyridine or 2phenylpyridine (Scheme 1).

\section{Experimental}

\subsection{Catalyst preparation}

$\mathrm{MnO}_{\mathrm{x}}$ and $\mathrm{CeO}_{2}$ were synthesized by the co-precipitation technique according to D'Alessandro et al. [16]. $\mathrm{MnO}_{\mathrm{x}}(\mathrm{Cu})$ and $\mathrm{CeO}_{2}(\mathrm{Cu})$ were prepared via the wet impregnation method according to Tang [17]. 


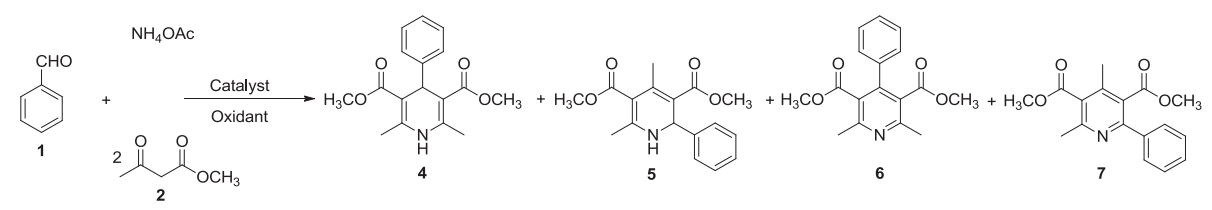

Scheme 1. Model reaction for the synthesis of 1,4-dihydropyridine or 2-phenylpyridine. Catalysts $=\mathrm{CeO}_{2}, \mathrm{CeO}_{2}(\mathrm{Cu}), \mathrm{MnO}_{\mathrm{x}}, \mathrm{MnO}_{\mathrm{x}}(\mathrm{Cu}) . \mathrm{Oxidant}=$ air atmosphere.

\subsection{Catalyst characterization}

FTIR spectra were measured on Bruker Vertex 70 accumulating 32 scans at a resolution of $4 \mathrm{~cm}^{-1}$. The XPS study was carried out in Multitechnique System equipment (SPECS) with a source of dual Xrays of $\mathrm{Mg} / \mathrm{Al}$ and a hemispheric analyzer PHOIBOS 150 operating in FAT (fixed analyzer transmission) mode. A qualitative determination of the strongest base sites was determined by Hammett indicators; $25 \mathrm{mg}$ of sample was shaken with $1 \mathrm{~mL}$ of a solution of Hammett indicator diluted in $10 \mathrm{~mL}$ methanol and left to equilibrate for $2 \mathrm{~h}$, after which no further color changes were observed [18].

\subsection{Catalytic test}

The Hantzsch reaction was carried out by stirring a mixture of $1 \mathrm{mmol}$ of benzaldehyde, $2 \mathrm{mmol}$ of methyl acetoacetate, $1.3 \mathrm{mmol}$ of ammonium acetate, and $50 \mathrm{mg}$ of the corresponding catalyst, without solvent, at $25,40,60,80$ and $100{ }^{\circ} \mathrm{C}$, respectively. The sample was collected from the reaction mixture during the reaction at time intervals. The analysis was performed on a gas chromatography Shimadzu 2014 instrument fitted with a $30 \mathrm{~mm} \times 0.32 \mathrm{~mm}$ SPB-1 capillary column.

\section{Results and discussion}

\subsection{Catalyst characterization}

In previous work D'Alessandro et al. [16] have described some characterization results. The results more relevant are summarized in Table 1. They have demonstrated: (i) the formation of Mn oxides and ceria and the presence of spinel of Cu by XRD; (ii) the BET surface area of $\mathrm{CeO}_{2}$ and $\mathrm{CeO}_{2}(\mathrm{Cu})$ is higher than that of $\mathrm{MnOx}$ and $\mathrm{MnOx}(\mathrm{Cu})$; (iii) a positive effect in the reducibility of $\mathrm{Mn}$ species with $\mathrm{Cu}$ incorporation, and (iv) the formation of highly dispersed $\mathrm{Cu}$ species on $\mathrm{MnO}_{\mathrm{x}}$ and $\mathrm{CeO}_{2}$ by TPR [16]. Full characterization by FTIR and XPS is presented in the Supplementary materials.

\subsection{Catalytic test}

Initially, the condensation of methyl acetoacetate, benzaldehyde and ammonium acetate as Hantzsch model reaction was examined comparatively at different temperatures, $25,40,60,80$ and $100{ }^{\circ} \mathrm{C}$ respectively, and the reaction selectivity was evaluated using the prepared catalysts $\left(\mathrm{CeO}_{2}, \mathrm{CeO}_{2}(\mathrm{Cu}), \mathrm{MnO}_{\mathrm{x}}\right.$ and $\left.\mathrm{MnO}_{\mathrm{x}}(\mathrm{Cu})\right)$ in solvent-free conditions.

In general, and as reported by Ananthakrishnan and Gazi [19], the Hantzsch reaction produces the corresponding 1,4-dihydropyridine 4 as the main product in the presence of the catalyst, solvent and heating. This is because the reaction proceeds via 1,4-addition (Michael-type), which is the thermodynamically favorable compound. Meanwhile, 2phenylpyridine 7 can be obtained as the main product at $20^{\circ} \mathrm{C}$, in an open atmosphere, under solvent, oxidant and catalyst-free conditions, in a long reaction time of $72 \mathrm{~h}$. In this case, the reaction proceeds through a 1,2-addition (kinetic control), and the reaction is a tandem reaction involving the construction of heterocyclic $\mathbf{5}$ and the aromatization to obtain 2-phenylpyridine $\mathbf{7}$ in the air presence as oxidant.

At first, we studied the reaction at $25^{\circ} \mathrm{C}$, and the optimum reaction conditions were examined employing benzaldehyde ( $1 \mathrm{mmol})$, methyl acetoacetate $(2 \mathrm{mmol})$, ammonium acetate $(1.2 \mathrm{mmol})$ and the catalyst $(50 \mathrm{mg})$. The catalysts were tested and notable reductions of the reaction time were observed in all cases, with respect to the blank experiment (Table 2, entry 1 ). The result shows a $\mathbf{4} / \mathbf{7}$ selectivity of $8 / 92 \%$ and the benzaldehyde conversion was $100 \%$ in $6 \mathrm{~h}$. Similar results were obtained with the other three catalysts as shown in Table 2, entries 3-5. The experiments performed at $25^{\circ} \mathrm{C}$ show that 2-phenylpyridine 7 can be obtained as the main product, in a short time period of $6 \mathrm{~h}$, compared with the result obtained without a catalyst at $60 \mathrm{~h}$ under the same reaction conditions. In this case, the reaction proceeds through a 1,2-addition (kinetic control) and the selectivity is only dependent on the reaction temperature, with no effect of the catalyst type tested being observed. For this reason, $25{ }^{\circ} \mathrm{C}$ is an excellent temperature for performing the selective synthesis of 2-phenylpyridine $\mathbf{7}$.

According to the literature, an increase in the reaction temperature increases the formation of 1,4-dihydropyridine 4 . For this reason, we performed the next experiments at 40 and $60^{\circ} \mathrm{C}$, respectively, to

Table 1

Some relevant characteristics of synthesized catalysts.

\begin{tabular}{|c|c|c|c|c|c|}
\hline Catalyst & XRD result & Surface area $\left(\mathrm{m}^{2} / \mathrm{g}\right)$ & Temperature of $\mathrm{H}_{2}$ consumption peaks $\left({ }^{\circ} \mathrm{C}\right)$ & $\mathrm{O} \alpha(\%)$ & Base strength \\
\hline $\mathrm{MnOx}$ & $\begin{array}{l}\mathrm{Mn}_{2} \mathrm{O}_{3} \\
\mathrm{MnO}_{2} \\
\mathrm{Mn}_{3} \mathrm{O}_{4} \\
\mathrm{Mn}_{5} \mathrm{O}_{8}\end{array}$ & 22 & $\begin{array}{l}338 \\
464\end{array}$ & 54.7 & $6-6.8$ \\
\hline $\mathrm{CeO}_{2}$ & $\mathrm{CeO}_{2}$ & 137 & 794 & 58.5 & $9,6-11,4$ \\
\hline $\mathrm{CeO}_{2}(\mathrm{Cu})$ & $\mathrm{CeO}_{2}$ & 138 & $\begin{array}{l}299^{\mathrm{a}} 344^{\mathrm{a}} \\
429 \text { (shoulder) } \\
763\end{array}$ & 50.5 & $5,4-6$ \\
\hline $\mathrm{MnOx}(\mathrm{Cu})$ & $\begin{array}{l}\mathrm{Cu}_{1.5} \mathrm{Mn}_{1.5} \mathrm{O}_{4} \\
\mathrm{Mn}_{2} \mathrm{O}_{3} \\
\mathrm{MnO}_{2} \\
\mathrm{Mn}_{3} \mathrm{O}_{4} \\
\mathrm{Mn}_{5} \mathrm{O}_{8}\end{array}$ & 29 & $\begin{array}{l}279^{\mathrm{a}} \text { (shoulder) } \\
343^{\mathrm{a}} \text { (shoulder) } \\
365\end{array}$ & 59.5 & $5,4-6$ \\
\hline
\end{tabular}

\footnotetext{
a Peaks assigned to dispersed Cu species.
} 
Table 2

Selectivity in the Hantzsch reaction at $25^{\circ} \mathrm{C}$ using the four synthesized catalysts.

\begin{tabular}{lllll}
\hline Entry & Catalyst & Time $(\mathrm{h})$ & Selectivity $\mathbf{4}(\%)$ & Selectivity $\mathbf{7}(\%)$ \\
\hline 1 & None & 60 & 13 & 87 \\
2 & $\mathrm{MnO}_{\mathbf{x}}$ & 6 & 8 & 92 \\
3 & $\mathrm{CeO}_{2}$ & 6 & 3 & 97 \\
4 & $\mathrm{MnO}_{\mathbf{x}}(\mathrm{Cu})$ & 6 & 9 & 91 \\
5 & $\mathrm{CeO}_{2}(\mathrm{Cu})$ & 6 & 12 & 88 \\
\hline
\end{tabular}

Reaction conditions: Benzaldehyde, $1 \mathrm{mmol}$; methyl acetoacetate, $2 \mathrm{mmol}$; ammonium acetate, $1.2 \mathrm{mmol}$; catalyst, $50 \mathrm{mg}$; solvent-free, $25{ }^{\circ} \mathrm{C}$; stirring. The conversion of benzaldehyde was $100 \%$ ( $1 \mathrm{~h}$ ). Conversion and selectivity were estimated by GC analysis. Selectivities of $\mathbf{5}$ and $\mathbf{6}$ were $0 \%$.

compare the conversion and selectivity of the synthesized catalysts. Table 3 shows the results obtained at $40{ }^{\circ} \mathrm{C}$ and Table 4 the ones corresponding to $60{ }^{\circ} \mathrm{C}$.

Table 3 , entry 3 , shows that the $4 / 7$ product selectivity of the reaction using $50 \mathrm{mg} \mathrm{CeO}_{2}$ was excellent (ratio 4/7 4/96\%). Similar to the result obtained at $25{ }^{\circ} \mathrm{C}$, the selectivity is slightly dependent on the catalyst type tested. The more selective catalyst was $\mathrm{CeO}_{2}$, which presents a 2-phenylpyridine 7 selectivity of $96 \%$ (Table 3 , entry 3 ). In all cases, the reaction is complete in $2 \mathrm{~h}$; therefore the $\mathrm{CeO}_{2}$ catalyst and this condition represent an excellent alternative for the selective synthesis of 2-phenylpyridine 7.

Table 4 lists the obtained results, using the initial reaction conditions at a temperature of $60{ }^{\circ} \mathrm{C}$. Also, an increase in 1,4-dihydropyridine 4 selectivity, with respect to the results obtained at 25 and $40{ }^{\circ} \mathrm{C}$, was observed. In this case, the reaction proceeds via 1,4-addition (Michaeltype), and 1,4-dihydropyrimidine $\mathbf{4}$ is the most thermodynamically favorable compound.

Another notable difference at $60{ }^{\circ} \mathrm{C}$ is that the reaction selectivity in product $\mathbf{4}$ or $\mathbf{7}$ changes and begins to be dependent on the catalyst used. For example, when we used the $\mathrm{CeO}_{2}$ catalyst, the selectivity of 1,4dihydropyridine 4 was $42 \%$ (Table 4, entry 3 ) and using $\mathrm{MnO}_{\mathrm{x}}$ the selectivity of $\mathbf{4}$ was only $24 \%$ and the selectivity of 2-phenylpyridine $\mathbf{7} 76 \%$ (Table 4, entry 2). It is remarkable that $\mathrm{CeO}_{2}$ starts to favor the formation of 1,4-dihydropyridine 4 .

Table 5 lists the obtained results, using the initial reaction conditions at a temperature of $80^{\circ} \mathrm{C}$. The catalysts were tested, and in all cases $1 \mathrm{~h}$ is the time required to obtain an aldehyde conversion of $100 \%$. Also, an increase in 1,4-dihydropyridine 4 selectivity with respect to the results obtained at $25,40{ }^{\circ} \mathrm{C}$, and $60{ }^{\circ} \mathrm{C}$ was observed. For example, when the $\mathrm{CeO}_{2}$ catalyst was used, a very good selectivity of $75 \%$ of $1,4-$ dihydropyridine 4 was obtained (Table 5, entry 3 ). For this reason, 80 ${ }^{\circ} \mathrm{C}$ is an excellent temperature for performing the selective synthesis of 1,4-dihydropyridine 4 .

The change of reaction selectivity observed at $80^{\circ} \mathrm{C}$ using the different synthesized catalysts could be interpreted comparing the acid-base properties. It is well known from the literature that an increase in the acidity or basicity of the catalyst and the reaction temperature improve the efficiency of the Hantzsch reaction for 1,4-dihydropyridine 4

Table 3

Selectivity in the Hantzsch reaction at $40{ }^{\circ} \mathrm{C}$ using the four synthesized catalysts.

\begin{tabular}{lllll}
\hline Entry & Catalyst & Time $(\mathrm{h})$ & Selectivity $\mathbf{4}(\%)$ & Selectivity $\mathbf{7}(\%)$ \\
\hline 1 & None & 30 & 23 & 77 \\
2 & $\mathrm{MnO}_{\mathrm{x}}$ & 2 & 16 & 84 \\
3 & $\mathrm{CeO}_{2}$ & 2 & 4 & 96 \\
4 & $\mathrm{MnO}_{\mathbf{x}}(\mathrm{Cu})$ & 2 & 7 & 93 \\
5 & $\mathrm{CeO}_{2}(\mathrm{Cu})$ & 2 & 5 & 95 \\
\hline
\end{tabular}

Reaction conditions: Benzaldehyde, $1 \mathrm{mmol}$; methyl acetoacetate, $2 \mathrm{mmol}$; ammonium acetate, $1.2 \mathrm{mmol}$; catalyst, $50 \mathrm{mg}$; solvent-free, $40{ }^{\circ} \mathrm{C}$; stirring. The conversion of benzaldehyde was $100 \%(2 \mathrm{~h})$. Conversion and selectivity were estimated by GC analysis. Selectivities of $\mathbf{5}$ and $\mathbf{6}$ were $0 \%$
Table 4

Selectivity in the Hantzsch reaction at $60{ }^{\circ} \mathrm{C}$ using the four synthesized catalysts.

\begin{tabular}{lllll}
\hline Entry & Catalyst & Time (h) & Selectivity 4 (\%) & Selectivity 7 (\%) \\
\hline 1 & None & 16 & 32 & 68 \\
2 & $\mathrm{MnOx}$ & 1 & 24 & 76 \\
3 & $\mathrm{CeO}_{2}$ & 1 & 42 & 58 \\
4 & $\mathrm{Cu} / \mathrm{MnOx}$ & 1 & 28 & 72 \\
5 & $\mathrm{Cu} / \mathrm{CeO}_{2}$ & 1 & 35 & 65 \\
\hline
\end{tabular}

Reaction conditions: Benzaldehyde, $1 \mathrm{mmol}$; methyl acetoacetate, $2 \mathrm{mmol}$; ammonium acetate, $1.2 \mathrm{mmol}$; catalyst, $50 \mathrm{mg}$; solvent-free, $60{ }^{\circ} \mathrm{C}$; stirring. The conversion of benzaldehyde was $100 \%(1 \mathrm{~h})$. Conversion and selectivity were estimated by GC analysis. Selectivities of $\mathbf{5}$ and $\mathbf{6}$ were $0 \%$.

production. In this case, an increase of the catalyst basicity could improve 1,4-dihydropyridine selectivity.

The catalysts synthesized in the present article have Lewis acid sites $\mathrm{M}^{+\mathrm{n}}$, Bronsted acid hydroxyl groups, and Lewis basic sites $\mathrm{O}^{-2}$ and $\mathrm{O}^{-}$. The principal difference between cerium and manganese catalysts is that the cerium catalyst presents basic sites of greater strength than the manganese catalyst. This characteristic was confirmed by a qualitative determination of the strongest basic sites by Hammett indicators and XPS techniques. The $\mathrm{pH}$ range obtained for the four catalysts were: $\mathrm{CeO}_{2}, 9.6<\mathrm{pH}<11.4 ; \mathrm{MnO}_{\mathrm{x}}, 6<\mathrm{pH}<6.8 ; \mathrm{CeO}_{2}(\mathrm{Cu}), 6<$ $\mathrm{pH}<6.8$; and $\mathrm{MnO}_{\mathrm{x}}(\mathrm{Cu}), 5.4<\mathrm{pH}<6$, respectively. Thus, $\mathrm{CeO}_{2}$ is the most basic catalyst of the series, and it showed high selectivity to $1,4-$ dihydropyridine 4.

Finally, to increase 1,4-dihydropyridine 4 selectivity, we performed the next experiment at $100{ }^{\circ} \mathrm{C}$. In all experiments, and using the four catalysts, the selectivity of 1,4-dihydropyridine 4 was less than $70 \%$, and some unidentified side products were detected by TLC. Particularly, in the catalyst $\mathrm{CeO}_{2}(\mathrm{Cu})$, where $\mathrm{Cu}$ was used as dopant agent, a secondary product $\mathbf{6}$ was detected, with a selectivity of $9 \%$. Product $\mathbf{6}$ is the result of the subsequent oxidation of 1,4-dihydropyridine 4 in the corresponding pyridine 6 . In this case $\mathrm{Cu}$ incorporation in the $\mathrm{CeO}_{2}$ catalyst improves its oxidant capacity. Several papers have reported that $\mathrm{Cu}$-doped $\mathrm{CeO}_{2}$ improves the oxidant capacity. The increased catalytic activity of $\mathrm{Cu}$-doped $\mathrm{CeO}_{2}$ is explained by the enhanced concentration and mobility of oxygen vacancies and the enhanced redox pair $\mathrm{Cu}^{+}$/ $\mathrm{Cu}^{2+}$ in the $\mathrm{CeO}_{2}$ : $\mathrm{Cu}$ system [20]. In addition, Prasad and Rattan reported that the high activity of $\mathrm{CuO}-\mathrm{CeO}_{2}$ is attributed to the quick reversible $\mathrm{Cu}^{2+/} \mathrm{Cu}^{+}$redox couples assisted by $\mathrm{Ce}^{4+} / \mathrm{Ce}^{3+}$ cycles [21].

In all the experiments, the $\mathrm{CeO}_{2}$ catalyst showed to be the most selective for obtaining 2-phenylpyridine 7 and 1,4-dihydropyridine 4. For this reason, it was used in two additional experiments for performing the preparative synthesis of both compounds using the optimized reaction conditions. When an appropriate mixture of three substrates and the catalyst was stirred at $40{ }^{\circ} \mathrm{C}$ under solvent-free conditions, the corresponding 2-phenylpyridine 7 was formed with $91 \%$ yield, in a reaction time of $6 \mathrm{~h}$. Under the same condition and at a temperature of $80^{\circ} \mathrm{C}$, the corresponding 1,4-dihydropyridine 4 was obtained with $74 \%$ yield in $1 \mathrm{~h}$, indicating that the $\mathrm{CeO}_{2}$ catalyst is effective to

Table 5

Conversion and selectivity in the Hantzsch reaction at $80{ }^{\circ} \mathrm{C}$ using the four synthesized catalysts.

\begin{tabular}{lllll}
\hline Entry & Catalyst & Time $(\mathrm{h})$ & Selectivity 4 (\%) & Selectivity 7 (\%) \\
\hline 1 & None & 12 & 30 & 70 \\
2 & $\mathrm{MnOx}$ & 1 & 44 & 56 \\
3 & $\mathrm{CeO}_{2}$ & 1 & 75 & 25 \\
4 & $\mathrm{MnOx}(\mathrm{Cu})$ & 1 & 48 & 52 \\
5 & $\mathrm{CeO}_{2}(\mathrm{Cu})$ & 1 & 66 & 34 \\
\hline
\end{tabular}

Reaction conditions: Benzaldehyde, $1 \mathrm{mmol}$; methyl acetoacetate, $2 \mathrm{mmol}$; ammonium acetate, $1.2 \mathrm{mmol}$; catalyst, $50 \mathrm{mg}$; solvent-free, $80^{\circ} \mathrm{C}$; stirring. The conversion of benzaldehyde was $100 \%(1 \mathrm{~h})$. Conversion and selectivity were estimated by GC analysis. Selectivities of 5 and 6 were $0 \%$. 
activate the formation of both products with the only change of reaction conditions.

The reusability of the $\mathrm{CeO}_{2}$ catalyst was investigated in the sequential reaction. The results, showed that the catalyst was reused four consecutive runs and no appreciate loss of its catalytic activity was observed $(74,73,73$ and $71 \%$ for $\mathbf{4}$, and $91,91,88$ and $87 \%$ for $\mathbf{7}$ ).

A plausible mechanism, similar to that reported in the literature using nano-sized $\mathrm{MgO}$ particles as catalyst, is presented in Fig. 1. The acid-base bifunctional sites of the catalyst facilitate the reaction, which can be visualized as proceeding through a Knoevenagel condensation product as a key intermediate (intermediate 1), a second key intermediate is an ester enamine (intermediate 2 ), which is produced by condensation of the second equivalent of the $\beta$-ketoester with ammonia, with further condensation between these two fragments giving the final product 4 .

\section{Conclusions}

The prepared materials were used as reusable catalysts, in a solventfree condition, for the multicomponent Hantzsch reaction between benzaldehyde, methyl acetoacetate, and ammonium acetate. A detailed study of the reaction temperature was performed in order to increase the selectivity of the two products, 1,4-dihydropyridine 4 and 2phenylpyridine 7. In both cases, the more selective catalyst was $\mathrm{CeO}_{2}$. 1,4-Dihydropyridine 4 was the main product formed at $80{ }^{\circ} \mathrm{C}$ and 2phenylpyridine 7 was the main product at $25^{\circ} \mathrm{C}$. In both processes, the catalyst was reused four consecutive runs and no appreciable loss of its catalytic activity was observed. The use of a solid acid catalyst instead of the usual soluble acid catalyst contributes to a reduction in waste generation by allowing an easy separation and recovery without any loss of its catalytic activity.

\section{Acknowledgments}

The authors are grateful to CONICET, UNLP and ANPCYT of Argentina for financial support.

\section{Appendix A. Supplementary data}

Supplementary data to this article can be found online at http://dx. doi.org/10.1016/j.catcom.2014.11.022.

\section{References}

[1] D.M. D'Souza, T.J.J. Müller, Chem. Soc. Rev. 36 (2007) 1095-1120.

[2] V. Estévez, M. Villacampa, J.C. Menéndez, Chem. Soc. Rev. 39 (2010) 4402-4421.

[3] H.M. Hügel, Molecules 14 (2009) 4936-4972.

[4] M.B. Gawande, R.K. Pandey, R.V. Jayaram, Catal. Sci. Technol. 2 (2012) 1113-1125.

[5] A.J. Fatiadi, Synthesis (1976) 65-104.

[6] Lj. Kundakovic, M. Flytzani-Stephanopoulos, J. Catal. 179 (1998) 203-221.

[7] S.M. Sajadi, M. Maham, R. Akbar, Lett. Org. Chem. 11 (2014) 49-54.

[8] A. Gharib, B.R.H. Khorasani, M. Jahangir, M. Roshani, R. Safaee, Org. Chem. Int. 2013 (2013) 1-5.

[9] L. Lamaita, M.A. Peluso, J.E. Sambeth, H.J. Thomas, Appl. Catal. B Environ. 61 (2005) 114-119.

[10] E. Poggio Fraccari, O. D'Alessandro, J. Sambeth, G. Baronetti, F. Mariño, Fuel Process. Technol. 119 (2014) 67-73.

[11] B. Maleki, R. Tayebee, M. Kermanian, S.S. Ashrafi, J. Mex. Chem. Soc. 57 (2013) 290-297 (and the references cited herein).

[12] C. Avendano, J.C. Menendez, Med. Chem. Rev. 1 (2004) 419-444.

[13] R. Mannhold, B. Jablonka, W. Voigt, K. Schönafinger, E. Schraven, J. Med. Chem. 27 (1992) 229-235.

[14] A. Sathicq, G. Romanelli, A. Ponzinibbio, G. Baronetti, H. Thomas, Lett. Org. Chem. 7 (2010) 511-518.
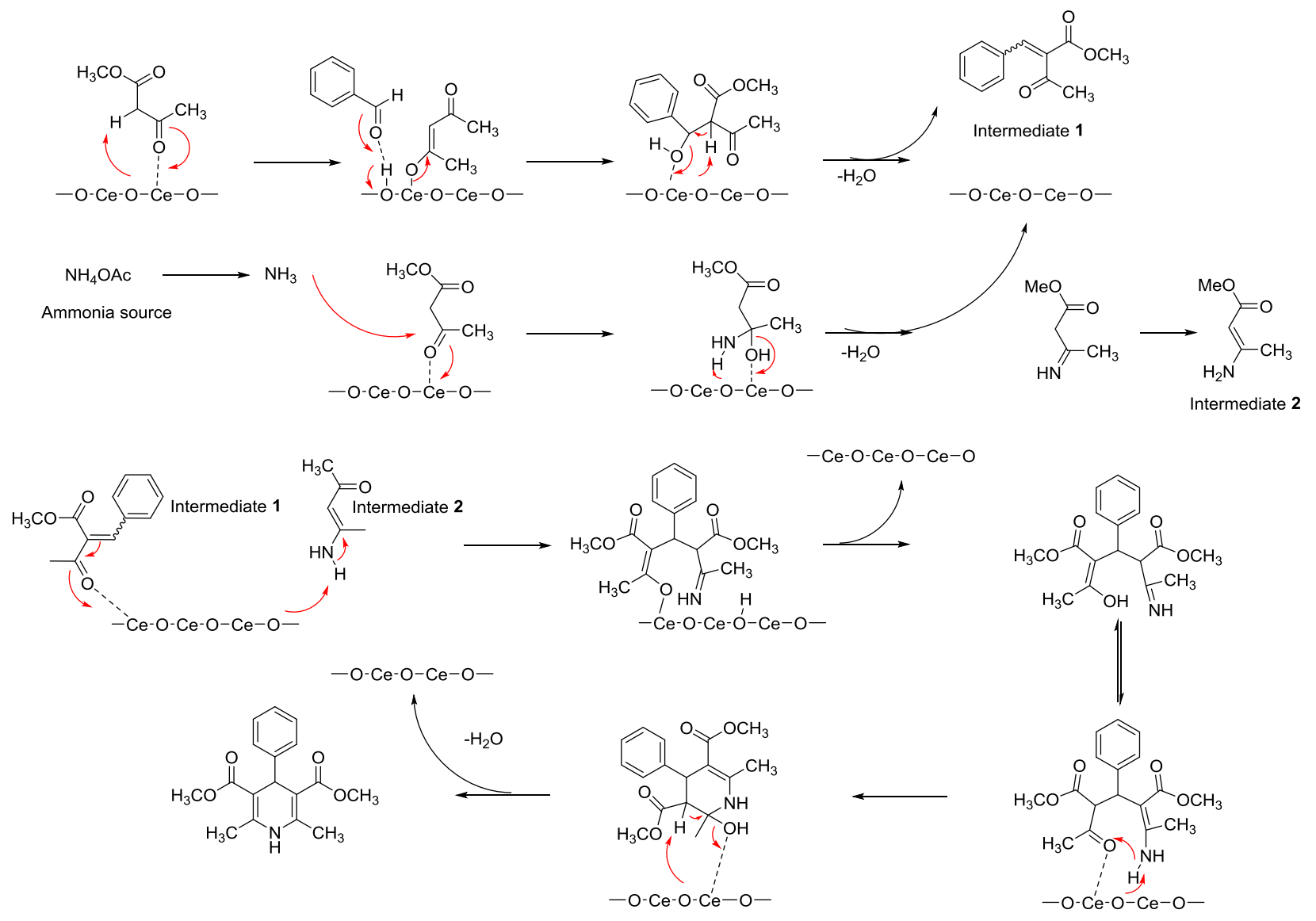

Fig. 1. Plausible mechanism for the formation of 1,4-dihydropyridines in the presence of $\mathrm{CeO}_{2}$. 
[15] L. Shen, S. Cao, J. Wu, J. Zhang, H. Li, N. Liu, X. Qian, Green Chem. 11 (2009) 1414-1420.

[16] O. D'Alessandro, H.J. Thomas, J.E. Sambeth, React. Kinet. Mech. Catal. 107 (2012) 295-309.

[17] X. Tang, J. Chen, Y. Li, Y. Li, Y. Xu, W. Shen, Chem. Eng. J. 118 (2006) 119-125.
[18] D.G. Cantrell, L.J. Gillie, A.F. Lee, K. Wilson, Appl. Catal. A Gen. 287 (2005) 183-190.

[19] R. Ananthakrishnan, S. Gazi, Catal. Sci. Technol. 2 (2012) 1463-1471.

[20] D. Zhang, Y. Qian, L. Shi, H. Mai, R. Gao, J. Zhang, W. Yu, W. Cao, Catal. Commun. 26 2012) 164-168.

[21] R. Prasad, G. Rattan, Bull. Chem. React. Eng. Catal. 5 (2010) 7-30. 